\title{
Native T1 lowering in iron overload and Anderson Fabry disease; a novel and early marker of disease
}

\author{
Daniel Sado ${ }^{1,2^{*}}$, Steven K White ${ }^{1,2}$, Stefan K Piechnik ${ }^{3}$, Sanjay M Banypersad ${ }^{1,2}$, Thomas A Treibel ${ }^{1,2}$, \\ Marianna Fontana ${ }^{1,2}$, Gaby Captur ${ }^{1,2}$, Viviana Maestrini ${ }^{1}$, Robin Lachmann ${ }^{4,2}$, Derralyn Hughes ${ }^{5}$, Elaine Murphy ${ }^{4,2}$, \\ John Porter ${ }^{2}$, Atul Mehta ${ }^{5}$, Perry Elliott ${ }^{1,2}$, James Moon ${ }^{1,2}$
}

From 16th Annual SCMR Scientific Sessions

San Francisco, CA, USA. 31 January - 3 February 2013

\section{Background}

T1 mapping is a powerful technique for ECV quantification; native $\mathrm{T} 1$ has been shown to increase in a variety of conditions including oedema, fibrosis and amyloid. Iron and fat lower T1. Anderson Fabry disease (AFD) is a fat storage disease, cardiac iron occurs in transfusion dependent patients. We hypothesised that T1 lowering would diagnose early cardiac involvement, track disease severity and discriminate from other mimic pathologies.

\section{Methods}

280 subjects were studied: iron overload $(\mathrm{n}=53)$, AFD ( $\mathrm{n}=44,55 \%$ with $\mathrm{LVH}$, all genotyped), healthy volunteers (HV, $\mathrm{n}=67,0 \%$ with LVH), hypertension (HYP, $\mathrm{n}=41,24 \%$ with $\mathrm{LVH})$, hypertrophic cardiomyopathy $(\mathrm{HCM}, \mathrm{n}=34$, $100 \%$ with $\mathrm{LVH}$ ), severe aortic stenosis (AS, $n=21,81 \%$ with $\mathrm{LVH}$ ) and definite AL cardiac amyloidosis (AMY, $\mathrm{n}=20,100 \%$ with $\mathrm{LVH})$. Along with routine clinical CMR, native, non-contrast T1 mapping was performed using the Sh-MOLLI technique at $1.5 \mathrm{~T}$ without gadolinium administration. T2*(iron overload) and LGE and LV mass (AFD and $\mathrm{LVH}$ diseases) were also assessed.

\section{Results}

Compared to health volunteers, septal T1 was lower in iron overload and AFD and higher in other diseases (iron overload vs AFD vs healthy volunteers vs other patients, $836 \pm 138 \mathrm{~ms}, 882 \pm 47 \mathrm{~ms}, 968 \pm 32 \mathrm{~ms}, 1018 \pm 74 \mathrm{~ms}$, $\mathrm{P}<0.0001)$.

${ }^{1}$ The Heart Hospital, London, UK

Full list of author information is available at the end of the article
In patients with $\mathrm{LVH}(\mathrm{n}=105), \mathrm{T} 1$ discriminated completely between AFD and all other diseases with no overlap (figure 1). In AFD, T1 correlated inversely with wall thickness $(\mathrm{R}=-0.51, \mathrm{P}=0.0004)$ and was abnormal in $40 \%$ of subjects even without LVH. Segmentally, AFD showed pseudo-normalisation or elevation of $\mathrm{T} 1$ in the LV infero-lateral wall, the extent correlating with the presence or absence of post contrast late gadolinium enhancement $(1001 \pm 82 \mathrm{~ms}$ vs $891 \pm 38 \mathrm{~ms}, \mathrm{P}<0.0001)$.

In iron overload, myocardial T1 strongly correlated with $\mathrm{T} 2 *(\mathrm{R}=0.87, \mathrm{P}<0.0001$, figure 2$)$. No patient with low $\mathrm{T} 2^{*}$ had normal $\mathrm{T} 1$, but $25 \%$ cases characterised by a normal $\mathrm{T} 2 *(\mathrm{n}=37)$ had low myocardial T1 (from 2 to 5 standard deviations below normal) suggesting a quarter of patients referred have mild iron loading despite a normal T2*

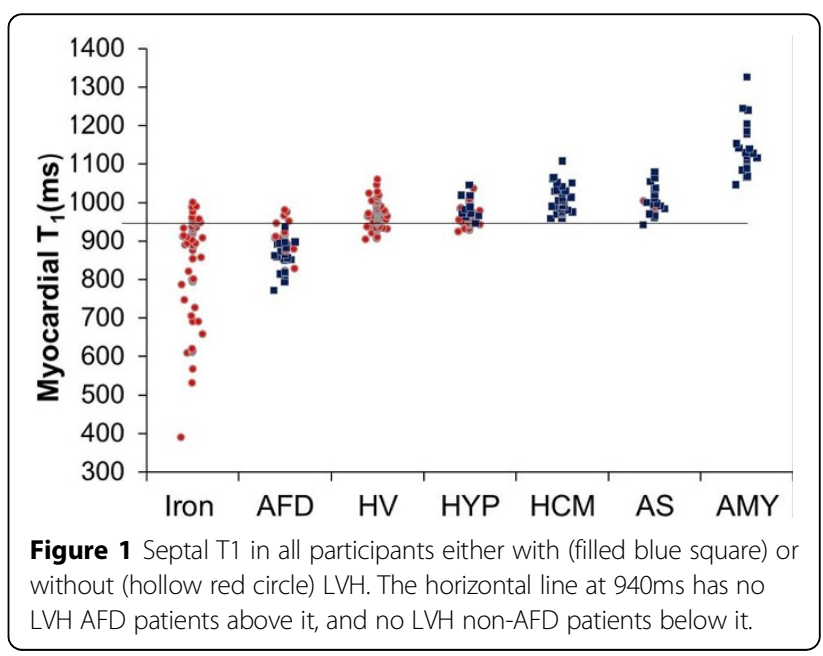

(c) 2013 Sado et al; licensee BioMed Central Ltd. This is an Open Access article distributed under the terms of the Creative Commons :HW Central Attribution License (http://creativecommons.org/licenses/by/2.0), which permits unrestricted use, distribution, and reproduction in any medium, provided the original work is properly cited. 


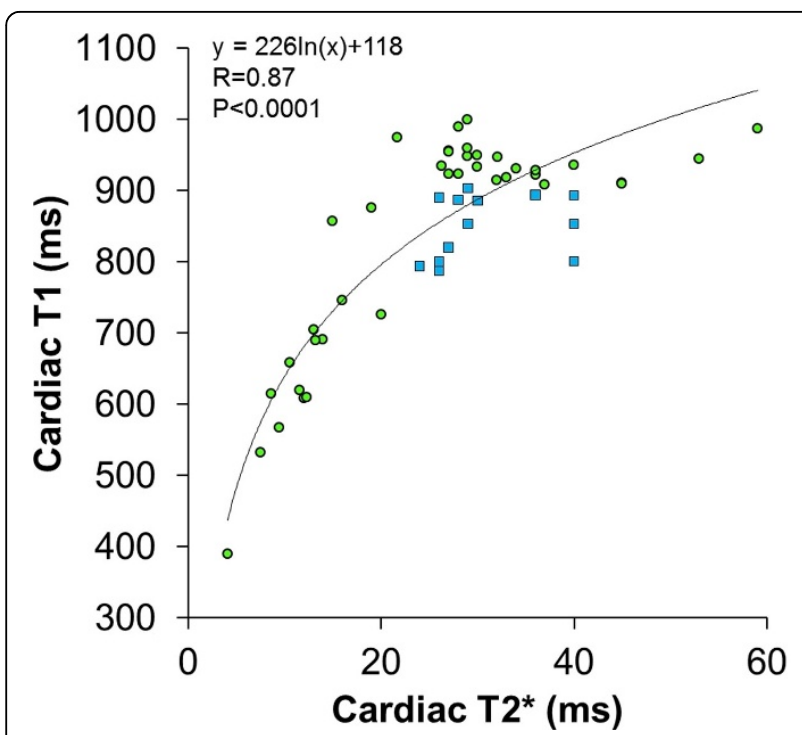

Figure 2 Cardiac septal T1 vs T2*. The filled blue square points show patients where the $\mathrm{T} 1$ was low despite a normal $\mathrm{T} 2^{*}$. The filled green circular points show patients where $\mathrm{T} 1$ and $\mathrm{T} 2^{*}$ were both normal, or both abnormal.

\section{Conclusions}

Impressive lowering of myocardial T1 can occur in AFD and particularly iron overloading. Unsuspected cardiac involvement was found in 40\% of AFD patients without $\mathrm{LVH}$ and $25 \%$ of possible iron overload patients where T2*was normal. When compared to the common causes of $\mathrm{LVH}$, the detection of $\mathrm{T} 1$ lowering appears definitively diagnostic of AFD.

\section{Funding}

1) British Heart Foundation.

2) Genzyme Pharmaceuticals.

\section{Author details}

${ }^{1}$ The Heart Hospital, London, UK. University College London, London, UK. ${ }^{3}$ University of Oxford, Oxford, UK. ${ }^{4}$ The National Hospital for Neurology and Neurosurgery, London, UK. ${ }^{5}$ Royal Free Hospital, London, UK.

Published: 30 January 2013

doi:10.1186/1532-429X-15-S1-071

Cite this article as: Sado et al: Native $\mathrm{T} 1$ lowering in iron overload and Anderson Fabry disease; a novel and early marker of disease. Journal of Cardiovascular Magnetic Resonance 2013 15(Suppl 1):071.

\section{Submit your next manuscript to BioMed Central} and take full advantage of:

- Convenient online submission

- Thorough peer review

- No space constraints or color figure charges

- Immediate publication on acceptance

- Inclusion in PubMed, CAS, Scopus and Google Scholar

- Research which is freely available for redistribution

Submit your manuscript at www.biomedcentral.com/submit
C Biomed Central 